El educador musical como agente de transformación social Páginas 29-42 en Revista de la Escuela de Ciencias DE LA EDUCACIÓN, AÑo 11, NÚMERO 10, ENERO A DICIEMBRE DE 2015. ISSN 1851-6297. ISSN EN LíNEA 2362-3349.

\title{
EL EDUCADOR MUSICAL COMO AGENTE DE TRANSFORMACIÓN SOCIAL
}

\author{
Por Vicente Eduardo Herrada* \\ Universidad Pedagógica Experimental Libertador - UPEL, Venezuela. \\ eduherr2006@hotmail.com \\ Por Fredy Enrique González** \\ Universidad Pedagógica Experimental Libertador - UPEL, Venezuela. \\ fredygonzalez1950@gmail.com
}

Recibido: 03/06/2014 Aceptado: 20/08/2014

\section{Resumen}

Los acontecimientos ocurridos durante siglos de historia dan cuenta de la influencia que ha tenido la música en los distintos escenarios de la vida del hombre, específicamente en el contexto político y social, donde el arte de los sonidos ha sido utilizado como elemento de aglutinación de masas y como símbolo de identificación de algunos movimientos sociales. Estos hechos muestran evidencias del efecto mental y emocional que ejerce la música en el individuo. Considerando estos supuestos, en el presente trabajo de base documental, se intenta develar la importancia que tiene el educador musical en la sociedad como elemento de transformación social a través de su praxis pedagógica, pues se presume, que este docente puede generar cambios sociales a través de la enseñanza y la práctica musical. Para ello, se hace un análisis reflexivo de algunos documentos teóricos científicos que aportan evidencias para pensar sobre la importancia que tiene la música en la conducta de las personas y de

* Magister en Educación Superior. Profesor de Lenguaje Musical y Armonía en el programa de Educación Musical de la Universidad Pedagógica Experimental Libertador (UPEL, Núcleo Maracay, Estado Aragua, Venezuela). Doctorando en Ciencias de la Educación de la UPEL Maracay; Director fundador de UPELJAZZ BAND, agrupación musical adscripta a la subdirección de extensión de la UPEL Maracay.

** Doctor en Educación; se desempeña como formador de profesores de Matemática en la Universidad Pedagógica Experimental Libertador (UPEL, Núcleo Maracay, Estado Aragua, Venezuela), donde es Coordinador del Doctorado en Educación Matemática y, también, Coordinador Fundador del Núcleo de Investigación en Educación Matemática "Dr. Emilio Medina" (NIEM). 
Revista de la Escuela de Ciencias de la Educación, año 11, número 10, enero a diciembre de 2015. PÁginas 29-42. ISSN 1851-6297. ISSN EN LINNEA 2362-3349. EL EDUCADOR MUSICAL COMO AGENTE DE TRANSFORMACIÓN SOCIAL. VICENTE Eduardo HerRada - Fredy EnRIQUe González

cómo este arte ha influido en el desarrollo y transformación de la sociedad y el mundo, en consecuencia se devela el papel que juega el educador musical al contar con tan poderoso instrumento de formación.

\title{
Palabras Clave:
}

Música - Sociedad - Movimientos sociales - Educador musical - Transformación social.

\section{MUSIC EDUCATORS AS AN AGENT OF SOCIAL TRASFORMATION}

\begin{abstract}
Throughout centuries, the events that had happened in history, tell us about the influence of music in the different scenarios of human life, specifically in the political and social context, in which the art of sound has been used as a binding element to unite the masses, and as an identifying symbol for some social movements. These facts show evidence of the mental and emotional effects that music has on the individuals. Given these assumptions, this work, based on evidence, tries to uncover the importance of the musical educator in society, as an element of social transformation using their pedagogical praxis, taking into account the presumption that teachers can generate social change through musical teaching and musical practice. In order to obtain these results, the analysis of some theoretical papers have been done, papers which provide scientific elements that help realizing the importance of music in people's behavior, and how this art has influenced the development and transformation of the world and society, consequently, the role of the musical educator who manages such powerful teaching tool, is revealed.
\end{abstract}

\section{Keywords:}

Music - Society - Social movements - Music educator - Social transformation.

\section{Introducción}

Partiendo de una revisión documental y de la experiencia en el área musical, así como también tomando en cuenta el ejercicio de la docencia durante años de los autores, mediante el presente trabajo se intenta develar la importancia que tiene el educador musical como agente de cambio social a través de la enseñanza y la práctica musical.

Este documento investigativo surge de una actividad académica perteneciente al curso de Sociopolítica y Educación del programa de Doctorado en Ciencias de la Educación que se dicta en la Universidad Pedagógica Experimental Libertador (UPEL) Maracay Venezuela, al cual los autores están vinculados académicamente.

La investigación se basa en el análisis reflexivo de documentos y escritos de carácter histórico científico inherentes al asunto de interés investigativo, 
Revista de la Escuela de Ciencias de la Educación, año 11, número 10, enero a diciembre de 2015. PÁginas 29-42. ISSN 1851-6297. ISSN EN LINEA 2362-3349. EL EDUCADOR MUSICAL COMO AGENTE DE TRANSFORMACIÓN SOCIAL. VICENTE Eduardo Herrada - Fredy EnRIQue González

donde se plantea cómo la música ha intervenido en los procesos de formación de diversos movimientos sociales y grupos culturales que han jugado un rol importante en diversos acontecimientos de orden político, cultural y social a nivel mundial, lo cual pone en evidencia el poder transformador y el efecto que ejerce el arte de los sonidos en las personas.

Asimismo se describen varios aspectos relacionados con la presencia de la música en el contexto político y social, cuya influencia se ha hecho sentir durante siglos de historia y muy especialmente, a partir de la década de los sesenta del siglo XX.

En un primer momento el documento se centra en la descripción de ciertos aspectos relevantes que dan cuenta de cómo históricamente, la música ha estado presente en distintos escenarios y contextos, actuando como factor asociado a los cambios ocurridos en la evolución de la sociedad, convirtiéndose en el elemento vinculante de importantes sucesos, los cuales han tenido lugar tanto en el ámbito político, como en lo social y cultural.

Seguidamente se plantea cómo el educador musical puede influir en sus estudiantes y actuar como agente de cambio a través de su praxis profesional, utilizando estrategias tales como el aprendizaje de canciones con contenidos líricos dirigidos a fines específicos, así como el ejercicio de la práctica instrumental.

En la tercera parte del documento se revisa el perfil del educador musical que se quiere y el que está egresando de las aulas universitarias, haciendo énfasis en el papel que juega en la sociedad el profesional de la educación musical y la responsabilidad que éste tiene ante sus educandos.

Finalmente, se concluye con algunas reflexiones donde los autores asumen su posición basándose en los argumentos emanados del análisis de los documentos referentes al asunto de interés indagatorio.

\section{La música en la transformación de conciencias}

La sociedad ha evolucionado en la medida que los acontecimientos asociados a los procesos de diversa naturaleza ocurridos en su seno, han ido generando cambios tanto a nivel individual como colectivo, esta dinámica evolutiva origina nuevas formas de pensar, sentir y actuar, afectando el comportamiento de los actores sociales y en consecuencia, estos han tenido que adaptarse a las normas derivadas de los cambios ocurridos en el tiempo.

Uno de los elementos más importantes y que ha tenido que ver con las transformaciones sociales en el mundo, debido al impacto que produce en las personas, es la música, en ese sentido, el efecto y el poder de disuasión de este arte es tal, que ha sido utilizado para diversos fines y en diferentes contextos. Por ejemplo, el arte musical como entretenimiento, ha adornado los salones de la alta sociedad, facilitando la eclosión jubilosa de la festividad; ha acom- 
Revista de la Escuela de Ciencias de la Educación, año 11, número 10, enero a diciembre de 2015. PÁginas 29-42. ISSN 1851-6297. ISSN EN LINEA 2362-3349. EL EDUCADOR MUSICAL COMO AGENTE DE TRANSFORMACIÓN SOCIAL. VICENTE Eduardo HerRada - Fredy EnRIQUe González

pañado las mesas de reyes, emperadores y gobernantes erigiéndose como la invitada de honor al banquete; asimismo, las combinaciones polirítmicas y sonoras musicales han apoyado el drama y el hecho dancístico, propiciando la fusión de géneros y ritmos, así como el intercambio entre diversas culturas.

En el campo religioso la música ha formado parte de diversas ceremonias piadosas y oficios funerarios; también ha cumplido una función comunicacional al servir de vehículo para la transmisión y difusión de las ideas espirituales de diferentes religiones que han visto en el arte musical la vía más directa para acercarse a Dios.

De esta manera, no existe escenario, espacio ni ámbito alguno donde la música no haya hecho sentir su efecto transformador. Al respecto, Martí (2010), agrega que:

La música toda, en sus diferentes formas de expresión, es una herramienta de trasformación social, y sobre esa premisa, nos guste o no, para bien o para mal, ha ido moldeando el gusto de todos aquellos millones y millones de habitantes que han sido invadidos por esa onda sonora mediatizada, cuyos ecos y resonancias han recorrido países y culturas del planeta. Todo hecho sonoro es susceptible de transformar al ser humano, desde su función fisiológica, sensible o cultural. (p.2)

Ciertamente, existen evidencias científicas del efecto de la música, el cual puede afectar profundamente la psiquis del individuo, originando así diferentes estados de ánimo, tales como alegrías, tristezas, nostalgia, gozo, dolor y angustia. Igualmente, a través de la música el sujeto puede experimentar cambios en su conducta, exaltando desde sus más puros sentimientos de amor y ternura, hasta los más profundos estados de rabia y violencia, e inclusive de odio.

Una muestra de lo antes expuesto, es el estudio dirigido por el Dr. Craig Anderson (2003), desarrollado por la Universidad Estatal de lowa y el departamento de servicios humanos de Texas. En este trabajo se evidenció cómo la música con letra violenta, genera estados de violencia en las personas, dicha investigación consistió en la realización de cinco experimentos con quinientos estudiantes, quienes fueron expuestos a siete canciones con letras violentas y ocho con líricas no violentas. El resultado reportó que cuando los participantes eran expuestos a la música con letra violenta, inmediatamente se incrementaba sus pensamientos y sentimientos agresivos, mientras que cuando escuchaban música con letras no violentas, no se generaba ningún cambio negativo en ellos.

Por otra parte, también se ha encontrado que la música por su poder de aglutinación de masas, ha sido considerada un medio efectivo para la transmisión masiva de mensajes e ideologías, por lo cual fue una de las armas de las que se valió el pueblo venezolano en la época independentista para expresar sus más profundos deseos de justicia; de tal modo que las melodías incendiarias 
Revista de la Escuela de Ciencias de la Educación, año 11, número 10, enero a diciembre de 2015. PÁginas 29-42. ISSN 1851-6297. ISSN EN LINEA 2362-3349. EL EDUCADOR MUSICAL COMO AGENTE DE TRANSFORMACIÓN SOCIAL. VICENTE Eduardo Herrada - Fredy EnRIQue González

y las canciones patrióticas no solo exaltaban el espíritu libertario de aquellas personas deseosas de libertad, sino que además, conquistaba el ánimo de aquellos que se mostraban indiferentes (Calcaño, 2007).

En este orden de ideas, la historia registra cómo en su sinfonía heroica, Bethoven muestra su simpatía por los ideales de la revolución francesa y su admiración por Napoleón, a quien dedicó la obra, dedicatoria que luego retiró al enterarse de la auto proclamación de Bonaparte como emperador. Asimismo, la obra musical de Richard Wagner fue tomada como bandera política por Hitler, quien fue un gran admirador del compositor alemán; de esta manera la música del maestro fue utilizada por los nazis en los campos de concentración para reeducar a los presos políticos (Fackler, 2007).

De acuerdo con Herrera (2011), la música, por su conexión con el ser humano y su relación con los pueblos del mundo lleva consigo una razón social y política que le da vida, por cuanto ésta, se identifica con la cultura en cualquier época y momento histórico; en su investigación, la autora refiere a una música con compromiso social e intencionalmente política.

También se puede apreciar cómo en el pasado más reciente esa conexión música-individuo se experimentó intensamente, sobre todo a partir de la convulsionada década de los sesenta del siglo XX, donde los ámbitos político, social, cultural, económico, religioso y todos los aspectos de la vida cotidiana de entonces, se vieron influenciados por una revolución musical sin precedentes. Así, en lo político, se puede observar como la canción y la música folclórica y popular latinoamericana, sirvió de medio para la transmisión de las ideologías propias de los partidos políticos y los gobiernos de esa época.

Estos eventos se deben quizás a que la canción es una de las formas musicales más sencillas y populares que el público común practica de manera natural y espontánea, por lo tanto, es la expresión más idónea y expedita para hacer llegar diversos mensajes al individuo, adentrándose de forma inadvertida, en su subconsciente. En ese sentido, Plaza (1966), hace referencia a la canción popular como el pan de cada día, puesto que cualquier persona común es capaz de explicar, más o menos de forma acertada, lo que esta significa.

Este gran musicólogo e investigador venezolano consideraba que "a través de la canción se llega a expresar un determinado estado de ánimo, que puede ser de tristeza, alegría, exaltación, humorismo, etcétera" (ob.cit, p.23); es tan cierta esta aseveración, que en los años sesenta y setenta del siglo pasado, la canción latinoamericana llegó a representar el instrumento ideal para difundir la ideología y el pensamiento para la formación del "hombre nuevo"; asimismo en Chile, bajo el lema canción "el pueblo unido jamás será vencido" cantores como Víctor Jara y los grupos Quilapayún e Inti Illimany se convirtieron en voceros musicales y fieles defensores del gobierno de Salvador Allende.

Por otra parte, la cantora Mercedes Sosa y los cantautores argentinos Facundo Cabral y Alberto Cortez, aunque no evidenciaban en su música nin- 
Revista de la Escuela de Ciencias de la Educación, año 11, número 10, enero a diciembre de 2015. PÁginas 29-42. ISSN 1851-6297. ISSN EN LINEA 2362-3349. EL EDUCADOR MUSICAL COMO AGENTE DE TRANSFORMACIÓN SOCIAL. VICENTE Eduardo HerRada - Fredy EnRIQUe González

guna tendencia política en particular, sus letras y melodías reflejaban un gran contenido filosófico con mensajes plenos de reflexión que despertaban en el oyente sentimientos de inconformidad existencial, pero a su vez auspiciaba el desarrollo de valores espirituales como la fe, la paz y la esperanza: "solo le pido a Dios que la guerra no me sea indiferente" M. Sosa; "querida mía, amada mía, ay patria mía" A. Cortez; "pobrecito mi patrón, piensa que el pobre soy yo" F. Cabral. En esas frases se sintetiza un poco el pensamiento filosófico de estos cantores, quienes a través de sus canciones marcaron una gran influencia en el pensamiento, el sentimiento y el espíritu de muchas personas, propiciando en ellos el ejercicio de la crítica reflexiva, potenciando a su vez la sensibilidad humana.

Los movimientos sociales desarrollados a partir de la segunda mitad del siglo XX, surgieron con gran fuerza, ejerciendo una marcada influencia en los cambios ocurridos en la sociedad. Curiosamente, las ideas y filosofías de estas agrupaciones, generalmente se erigían en torno a un estilo o una corriente musical específica, sobre la cual sustentaban sus ideas y filosofía de vida, tal es el caso del movimiento hippie surgido en los años sesenta bajo el concepto de la contracultura, revelándose contra el sistema político y la sociedad de consumo, además de abogar por el antibelicismo y su oposición ante la indetenible guerra de Vietnam (Stone, s.f).

Los hippies adoptaron el rock como símbolo de identidad, de tal manera que cantantes como Janet Joplin, Jimmy Hendrix, Bob Dylan, entre otros, emergieron como iconos de la más alta expresión de esta tendencia social, amen de la influencia de los Beatles quienes fueron los principales protagonistas de la música que sacudió al mundo.

El rastafari por su parte, es un movimiento religioso importante del siglo XX, el cual se originó al inicio de los años treinta en África, instalándose inmediatamente en Jamaica. Este movimiento se identificaba con el culto al dios Jah, personificado por el emperador Haile Selassie, además utilizaban la marihuana en sus rituales, cuyo consumo armonizaba el ambiente, elevando a los creyentes a misteriosos estados de paz y amor, por lo que consideraban a esta droga como "la hierba sagrada" (Serbin, 1986).

Como es mundialmente conocido, el reggae es la música representativa de los rastas; se trata de una especie de fusión entre la música tradicional jamaiquina, el rithm and blues, el jazz y el ska. Las letras enmarcadas en estos ritmos y la fama de Bob Marley contribuyeron a la difusión por todo el mundo del movimiento, el cual ha tenido un gran repunte en las primeras décadas del presente siglo XXI.

Esta breve narrativa histórica es una muestra de la influencia que ha ejercido la música en el ser humano y en el desarrollo de la sociedad; la intervención del hecho artístico musical en múltiples y complejos contextos como son el político, social y cultural, ha llegado a convertirse en factor importante 
Revista de la Escuela de Ciencias de la Educación, año 11, número 10, enero a diciembre de 2015. PÁginas 29-42. ISSN 1851-6297. ISSN EN LINEA 2362-3349. EL EDUCADOR MUSICAL COMO AGENTE DE TRANSFORMACIÓN SOCIAL. VICENTE Eduardo Herrada - Fredy EnRIQue González

en muchas de las decisiones colectivas que han originado cambios, y han marcado de alguna manera, los caminos a través de los cuales se ha conducido el rumbo de la historia.

Por ello, la enseñanza y la práctica de la música en el contexto escolar, puede aportar soluciones a muchos problemas de orden cognitivo, emocionales e inclusive físicos, contribuyendo así a la formación de un individuo sano, capaz y honesto; esto es posible claro está, sólo si el proceso de formación musical es conducido de manera responsable, de allí la importancia que tiene el educador musical en su rol de agente de transformación social quien puede mediante una praxis consciente, crear el ambiente para propiciar cambios positivos en las personas.

\section{El Educador Musical: catalizador de multitudes}

En atención a los argumentos antes expuestos, se considera que el educador musical tiene en sus manos una poderosa arma de construcción masiva, y en tal sentido, es menester analizar el papel que juega en la sociedad este hacedor de sueños, considerando la importancia que tiene la música en su praxis pedagógica.

En su ejercicio profesional el especialista de educación musical interactúa con cientos de niños y jóvenes del sistema educativo, y desde el mismo momento en que se produce dicha interacción este docente se convierte en un factor de cambio social, pues a través del contacto diario con sus estudiantes y la aplicación de la música como herramienta de formación, este tiene la oportunidad de moldear y/o modificar las conductas, así como de inducir a sus discípulos hacia determinadas formas de sentir, pensar, actuar y conducirse.

El canto por ejemplo es una actividad que el educador musical debe ejercitar a diario en el aula, de tal manera que, mediante la práctica de canciones infantiles, folclóricas y populares, se puede inculcar en los niños el sentido de pertenencia, el fomento de valores, el sentimiento nacionalista, el amor por la familia y la naturaleza, en fin, la correcta forma de vivir y servir a la sociedad.

No obstante, así como esta práctica puede significar una estrategia efectiva para inculcar valores humanos e impulsar el desarrollo intelectual y espiritual de los niños, jóvenes y adultos, el uso inadecuado de la misma, bien sea consciente o inconscientemente, puede causar un impacto psicológico en el individuo y generar actitudes y conductas no deseadas; en relación a ello, se ha comprobado científicamente que detrás de una imagen, una letra o una melodía aparentemente inofensiva, pueden esconderse intereses oscuros con la finalidad de lograr un propósito determinado, obteniendo, a través de los más variados mensajes subliminales, fines y objetivos específicos.

Al respecto se puede decir que los mensaje subliminales son aquellos que aunque no sean captados conscientemente, inciden en el pensamiento, 
Revista de la Escuela de Ciencias de la Educación, año 11, número 10, enero a diciembre de 2015. PÁginas 29-42. ISSN 1851-6297. ISSN EN LINNEA 2362-3349. EL EDUCADOR MUSICAL COMO AGENTE DE TRANSFORMACIÓN SOCIAL. VICENTE Eduardo HerRada - Fredy EnRIQUe González

emociones o conductas de los individuos (Queraltó, 1997), debe ser por ello que esta técnica, por llamarla de alguna manera, ha sido utilizada hasta la saciedad con fines publicitarios, políticos y de recreación de imágenes.

Es oportuno el momento para citar una de las canciones infantiles más tradicionales de la historia musical contemporánea, que cientos de personas de diferentes generaciones han cantado prácticamente desde que emitieron sus primeros balbuceos; se trata de la canción Arroz con leche, donde se invita al pretendiente a casarse con una viudita que sepa coser, que sepa planchar y que ponga la mesa en su santo lugar; es decir no te cases por amor, sino porque necesitas de alguien que te atienda y te sirva; allí se puede evidenciar el mensaje dirigido al incremento de la mentalidad machista practicada en algunos sectores de la sociedad.

Por otra parte, en algunas de las canciones pertenecientes al repertorio del cancionero escolar, editado por el Ministerio de Educación de Venezuela a finales de la década de los sesenta y principios de los setenta, se deja entrever en los contenidos de las letras de algunas de las canciones, una carga subliminal que puede sugerir la adopción de ciertas posturas y actitudes en quien las canta y quien las escucha; como por ejemplo, "Oligarcas temblad" (mensaje político); "El santiguao" (sincretismo religioso); "El Negrito" (con discriminación racial). (Mis Canciones Escolares, 1975)

Los niños cual esponja son susceptibles de absorber los conocimientos y fijarlos en su estructura cognitiva de forma permanente, analizándolos e interpretándolos de acuerdo con su madurez mental; además, son los niños y los jóvenes los más sensibles y manipulables mentalmente, y por ser ellos potenciales receptores de los mensajes inscritos en las letras de muchas canciones, son blanco fácil para penetrar en sus subconscientes y lograr mediante la perversa técnica subliminal, oscuros objetivos.

Otro claro ejemplo de manipulación mental se observa en la música comercial actual, a la que los jóvenes y niños de hoy están expuestos; de este modo, géneros musicales como el rock, reggaetón, vallenato y otros tantos géneros y estilos musicales, son utilizados regularmente para insertar en sus cadenciosos ritmos, algunos mensajes cuyo contenido, en muchos casos, incitan a la violencia, al sexo, al consumismo y a la adoración de infinidades de falsos dioses.

Por las razones expuestas, es importante que el docente esté alerta y se cerciore de la calidad de los contenidos que está desarrollando en su clase, a fin de propiciar un aprendizaje musical y una práctica del canto de manera sana y consciente, lo cual permitiría contrarrestar y combatir toda la carga negativa que tienen muchas de aquellas canciones con contenidos aparentemente inofensivos, las cuales muchos niños, jóvenes y adultos en el mundo cantan y escuchan a diario. 
Revista de la Escuela de Ciencias de la Educación, año 11, número 10, enero a diciembre de 2015. PÁginas 29-42. ISSN 1851-6297. ISSN EN LINEA 2362-3349. EL EDUCADOR MUSICAL COMO AGENTE DE TRANSFORMACIÓN SOCIAL. VICENTE Eduardo Herrada - Fredy EnRIQue González

Es necesario que el educador musical se prepare antes de abordar cualquier contenido que desee desarrollar con sus estudiantes y en ese sentido, debe ser un investigador, que haga de la investigación una práctica permanente, ello garantizaría en gran medida, que el conocimiento que se está desarrollando sea idóneo, sano y provechoso para lograr en los educandos una formación apegada a los valores espirituales y morales que la sociedad exige.

De este modo, el docente de música debe hacerse de técnicas y estrategias novedosas para desarrollar su trabajo, nutrir sus propias ideas con las propuestas de los grandes pedagogos musicales del siglo $\mathrm{XX}$ tales como Dalcroze, Orff, Suzuki y Willems, (por nombrar sólo algunos), quienes hicieron valiosos aportes a la enseñanza musical a través de la implementación de estrategias didácticas originales y recursos de avanzada, destacando en sus propuestas pedagógicas la importancia que tiene la música para transmitir valores y desarrollar las capacidades del ser humano.

El efecto que produce la música en el individuo ha quedado demostrado, toda vez que en los últimos años gracias a la puesta en marcha de diversos proyectos y programas de orden pedagógico musicales basados en la formación integral del ser humano, es decir "música para la acción social"...porque indudablemente la música "es un instrumento irremplazable para unir a las personas" (Abreu, 2011). Ciertamente, proyectos musicales como el del Sistema Nacional de Orquestas Juveniles e Infantiles de Venezuela (FESNOJIV), impulsado por el maestro Abreu, plantea una propuesta pedagógica basada no sólo en la formación artística sino en la formación humana (Abreu, ob. cit).

Este proyecto musical ha permitido la aglutinación de miles de niños, niñas y jóvenes de todos los estratos sociales, inclusive de aquellos provenientes de la calle y de las llamadas zonas marginadas, violentas y de hogares desarticulados producto de la descomposición social, de manera tal que al integrarse a la práctica musical colectiva, estos tengan la oportunidad de interactuar con sus semejantes y desenvolverse en escenarios propicios para el desarrollo de una vida sana y más humana.

De acuerdo con este planteamiento, Cabedo (2009), agrega que las dimensiones sociales de la música van más allá del hecho artístico, y su gran utilidad estriba en lo concerniente a la formación de la personalidad, al despertar de la mente, el desarrollo de la sensibilidad y de la capacidad de comunicación. Además, al referirse al sistema de orquestas juveniles e infantiles, el autor citado refiere que "en la esfera personal es relevante el desarrollo espiritual, moral, intelectual y afectivo de los niños y niñas, adolescentes y jóvenes involucrados en este gran programa musical" (p.7)

Efectivamente, la práctica instrumental es una actividad mediante la cual el educador musical puede desarrollar muchos de esos valores, propiciando el trabajo en equipo, el compañerismo, la solidaridad, la responsabilidad y el trabajo creador, asimismo, a través de esta actividad el docente musical tiene 
Revista de la Escuela de Ciencias de la Educación, año 11, número 10, enero a diciembre de 2015. PÁginas 29-42. ISSN 1851-6297. ISSN EN LINNEA 2362-3349. EL EDUCADOR MUSICAL COMO AGENTE DE TRANSFORMACIÓN SOCIAL. VICENTE Eduardo HerRada - Fredy EnRIQUe González

la oportunidad de descubrir los talentos musicales y futuros instrumentistas, quienes podrán disfrutar del arte musical y desarrollar sus capacidades musicales al tiempo que ejercitan la la integración, la socialización y la interacción en ambientes sanos y favorables para su desarrollo humano.

\section{El Educador Musical que se requiere}

Diversas teorías científicas han intentado destacar las capacidades de las cuales está dotado el ser humano; por ejemplo, Gardner en su teoría de las inteligencias múltiples, explica que hay ciertas partes del cerebro que desempeñan papeles importantes en la percepción y la producción musical, y aquellos que se conectan con esta parte del hemisferio cerebral, son capaces de desarrollar la inteligencia musical, es decir, son personas a quienes se les facilita entonar una melodía, amen de tener cierta afinidad con el ritmo y una gran habilidad para ejecutar instrumentos musicales (Gardner, 2002).

Evidentemente todos los seres humanos por naturaleza somos creaturas inteligentes y desarrollamos un gran potencial creativo, y aunque poseamos en gran parte una inteligencia musical, el ser músico profesional va más allá del ser creativo o poseer una buena condición auditiva (oído musical), más bien este hecho implica una serie de condiciones de tipo aptitudinal (capacidad de reconocimiento audio perceptivo, habilidades rítmicas y de coordinación motriz, creatividad, capacidad memorística para el aprendizaje de melodías, canciones y obras musicales; capacidad perceptual (para el análisis y reproducción de partituras musicales) y actitudinal (disposición para adaptarse a las exigencias derivadas de la práctica musical); por último, lo más importante, el músico debe tener convicción y una clara conciencia sobre el compromiso, el significado y la importancia que tiene el ser músico profesional.

Ahora bien, el estudio de la docencia musical como carrera profesional implica un doble compromiso para quien desea ejercerla, pues esta especialidad exige por una parte, el aprendizaje y dominio de los elementos generales de la música, así como el desarrollo de un componente docente que implica el dominio de los aspectos inherentes a las teorías del aprendizaje, la didáctica y el conocimiento de los principios fundamentales de la filosofía, la psicología y demás aspectos tratados por la ciencia de la educación.

La Universidad Pedagógica Experimental Libertador (UPEL) de Venezuela, es una de las instituciones donde se forman educadores en diversas áreas, en ese abanico de opciones formativas, se ofrece la carrera de educación musical dirigida a aquellos aspirantes que desean formarse en esta especialidad. El proceso de formación comprende básicamente dos grandes componentes: uno dirigido hacia el hecho pedagógico, donde el estudiante recibe todas las herramientas pedagógicas y didácticas para el buen ejercicio de la enseñanza, y otro enfocado hacia la formación especializada, donde se le capacita en todo 
Revista de la Escuela de Ciencias de la Educación, año 11, número 10, enero a diciembre de 2015. PÁginas 29-42. ISSN 1851-6297. ISSN EN LINEA 2362-3349. EL EDUCADOR MUSICAL COMO AGENTE DE TRANSFORMACIÓN SOCIAL. VICENTE Eduardo Herrada - Fredy EnRIQue González

lo que corresponde a la parte musical, la cual, el docente especialista egresado debe dominar en su totalidad.

De esta manera, el profesional egresado en educación musical de la UPEL debe haber adquirido a lo largo de su formación, los conocimientos básicos en su área de especialización que le permitan desempeñarse con éxito en su práctica docente, y en tal sentido, el perfil específico del egresado plantea cuales son esos requerimientos mínimos exigidos.

Uno de los planteamientos esbozados en el perfil general del egresado de la especialidad de educación musical descrito en el diseño curricular de la UPEL (1997), el cual es oportuno citar a fin de fortalecer esta disertación, sugiere que el educador musical debe ser un profesional capaz de conducir el desarrollo integral de los niños, niñas y jóvenes facilitando su progreso social y cultural, además, debe conocer la realidad educativa y los factores económicos, políticos y culturales del país y de su localidad, convirtiéndose por lo tanto en un agente de cambios.

En síntesis, interpretando las líneas marcadas en cursivas, es menester destacar el papel de gestor social que el perfil general del egresado destaca claramente y que define un poco el profesional que se quiere; es decir, un profesional competente, consciente de la realidad social, de la responsabilidad y del papel que juega en la sociedad, donde este asuma el hecho cultural con una actitud critica, reflexiva; con una conciencia abierta a la posibilidad de generar los cambios que fortalezcan la sociedad y los actores sociales con quien les corresponda interactuar.

Lo que se quiere dilucidar con lo antes expuesto, es la relación que existe entre el educador musical que se está formando en las aulas y aquel que se requiere para cumplir con la función de un agente de transformación social. Es así como el asunto de interés investigativo abordado en este trabajo y el planteamiento traído a colación en el desarrollo del documento, es un tema que requiere de una profunda revisión por parte de investigadores y docentes del área de las artes musicales, para de esta manera destacar la importancia que tiene la enseñanza y la práctica de la música, la cual sin duda alguna constituye un instrumento socializador y transformador.

\section{Reflexiones finales}

A través de siglos de historia ha quedado en evidencia el poder de la música y su efecto socializador y trasformador de conciencias, lo cual ha influido en las sociedades de distintas épocas. En los escritos bíblicos por ejemplo, existen algunos relatos que dan cuenta de ello, como es el caso de la caída de los muros de la ciudad de Jericó atribuida a la potencia de las trompetas de los sacerdotes de Israel (Josué cap. VI, vv 1-21); así mismo los griegos y los 
Revista de la Escuela de Ciencias de la Educación, año 11, número 10, enero a diciembre de 2015. PÁginas 29-42. ISSN 1851-6297. ISSN EN LINEA 2362-3349. EL EDUCADOR MUSICAL COMO AGENTE DE TRANSFORMACIÓN SOCIAL. VICENTE Eduardo HerRada - Fredy EnRIQUe González

egipcios atribuían poderes sobrenaturales a la música por considerar que ésta provenía de los dioses y de las musas, de allí el origen del término.

Por otra parte, en sus diálogos Platón hablaba de la importancia de la música para la formación del alma y la colocaba en un alto grado de supremacía sobre las demás artes, otorgándole una gran importancia en la educación del hombre; además Aristóteles señalaba los tres usos provechosos de la música: para la educación, la purificación y el divertimiento como un placer noble. (Espinar, 2011).

De este modo, es inconcebible que en pleno siglo XXI, a pesar de la globalización, el desarrollo de las nuevas tecnologías y el acceso de millones de usuarios a las redes sociales de comunicación, lo cual ha generado una gran oleada informativa en todos los ámbitos y niveles, muchas personas desconocen, o no están conscientes, de la influencia que tiene y ha tenido la música en la evolución del hombre, así como los beneficios que en lo espiritual y en la salud física y mental puede aportar el buen uso y la práctica del arte musical.

Promover las bondades y la importancia que tiene la música para el ser humano es una labor que debe emprender el docente de música desde que inicia su transitar académico, y en ese sentido, es necesario que desde sus aulas, los docentes musicales dirijan sus esfuerzos hacia la consolidación de este hecho; también es necesario que los especialistas de música asuman de manera consciente la importante misión que conlleva ser un docente de esta área y desde la perspectiva de la función social de la educación artística transformadora, se valore el compromiso que conlleva el ejercicio de tan relevante tarea.

De esta manera, el mundo actual demanda que desde la formación del educador musical se analice la importancia que tiene el asumir esta carrera como profesión y se reflexione sobre los benévolos efectos de la música, y que no se siga viendo sólo como un divertimento o un mero pasatiempo, sino más bien como una herramienta valiosa y eficaz para generar cambios en el individuo mediante la formación del nuevo ser humano, en quien en manos está la responsabilidad de la construcción de la nueva sociedad.

\section{Referencias Bibliográficas}

- $\quad$ Abreu, J.A. (2011). La cultura para los pobres no puede ser una pobre cultura. El País. Recuperado de http://elpais.com/diario/2011/10/30/eps/1319956014_850215.html.

- $\quad$ Anderson, C. \& Carnagey N. (2003). Exposure to violent media: the effects of songs with violent lyrics on feelings, aggressive thoughts and feelings. Journal of Personality and Social Psychology, 84 (5), 960-971. Recuperado de http://www.psychology.iastate.edu/ faculty/caa/abstracts/2000-2004/03ACE.pdf.

- Cabedo, A. (2009). La educación musical como modelo para una cultura de paz. Universitat Jaume. (1), 4-7.Recuperado de http://uji.es/bin/publ/edicions/jfi14/psicoped/3.pdf.

- Calcaño, J.A. (2007). Contribución al estudio de la música en Venezuela. Caracas: Fundación Editorial El Perro y La Rana. 
Revista de la Escuela de Ciencias de la Educación, año 11, número 10, enero a diciembre de 2015. Páginas 29-42. ISSN 1851-6297. ISSN EN LINEA 2362-3349. EL EDUCADOR MUSICAL COMO AGENTE DE TRANSFORMACIÓN SOCIAL. VICENTE Eduardo Herrada - Fredy EnRIQue González

- $\quad$ Espinar, J.L. (2011). Una aproximación a la música griega antigua. Tramyris 2, 141-157. Recuperado de http//www.thamyris2/Espinar.pdf.

- $\quad$ Fackler, G. (2007). Music in concentration camps 1933-1945. Music and the Holocaust Londres Reino Unido: ORT. Recuperado de http://www.music.ucsb.edu/projects/musicandpolitics/archive/2.

- Gardner, E. (2002). Inteligencias múltiples. La teoría en la práctica. Recuperado de http:// ict.edu.ar/renovacion/wp-content/uploads2012/02. Grdner_inteligencia.pdf.

- Herrera, S. (2011). Un acercamiento al estudio y análisis de la relación Música-Política. Folios. 4 (23), 46-53. Recuperado de http://web.iepcjalisco.org.mx/sites/default/files.

- Martí, L. (2010). La música de raíz folklórica como herramienta de transformación social. En Fabio Erreguerena (Presidencia). Conferencia llevada a cabo en el IV congreso Nacional de Extensión Universitaria. Mendoza, Argentina.

- Ministerio de Educación. (1975). Cancionero escolar venezolano. Departamento de Publicaciones. Caracas: Autor.

- Paraskevaídis, G. (2008). Algunas reflexiones sobre música y dictadura en América Latina. Recuperado de http://www.gp-magma.net/pdf/txt_e/sitio-MusyDicfinal2008.pdf.

- $\quad$ Plaza, J.B. (1966). El lenguaje de la música. Lecciones populares sobre música. Caracas: Universidad Central de Venezuela. Dirección de Cultura.

- Queraltó, J. M. (1.997). Mensajes que no llegan a la conciencia. Recuperado de http:/l hipatia.uab.cat/jmoix/vansubli.pdf.

- Stone, S. (s.f). Hippy activism. Recuperado de http://www.hippplanet.com/books/atos/ activism.htm.

- $\quad$ Serbin, A. (1986). Los Rastafari: entre mesianismo y revolución. Nueva Sociedad. 82, 178-186. Recuperado de http://www.nuso.org/upload/articulos/1384_pdf.

- Universidad Pedagógica Experimental Libertador. (1997). Diseño Curricular. Componente de Formación Especializada, Educación Musical. Caracas: Autor.

- Velasco, F. (2007). La nueva canción latinoamericana. Notas sobre su origen y definición. Presente y Pasado, 12 (23), 139-153. 